\title{
Investigations into microsporidian methionine aminopeptidase type 2: a therapeutic target for microsporidiosis
}

\author{
Hong Zhang ${ }^{1}$, Huan Huang ${ }^{1}$, Ann Cali ${ }^{2}$, Peter M. Takvorian ${ }^{2}$, Xiaochuan Feng $^{3}$, Ghou Zhou ${ }^{4}$ and \\ Louis M. Weiss ${ }^{1,5}$ \\ ${ }^{1}$ Departments of Pathology, ${ }^{4}$ Biochemistry, and ${ }^{5}$ Medicine, Albert Einstein College of Medicine, Bronx, New York 10461, USA; \\ ${ }^{2}$ Department of Biologic Sciences, Rutgers University, Newark, New Jersey 07102, USA; \\ ${ }^{3}$ Division of Infectious Diseases, Tufts University School of Veterinary Medicine, North Grafton, Massachusetts 01536, USA
}

Key words: Microsporidia, methionine aminopeptidase type 2, MetAP2, Enterocytozoon, Encephalitozoon, Brachiola, therapeutics

\begin{abstract}
The Microsporidia have been reported to cause a wide range of clinical diseases particularly in patients that are immunosuppressed. They can infect virtually any organ system and cases of gastrointestinal infection, encephalitis, ocular infection, sinusitis, myositis and disseminated infection are well described in the literature. While benzimidazoles such as albendazole are active against many species of Microsporidia, these drugs do not have significant activity against Enterocytozoon bieneusi. Fumagillin, ovalicin and their analogues have been demonstrated to have antimicrosporidial activity in vitro and in animal models of microsporidiosis. Fumagillin has also been demonstrated to have efficacy in human infections due to E. bieneusi. Fumagillin is an irreversible inhibitor of methionine aminopeptidase type 2 (MetAP2). Homology cloning employing the polymerase chain reaction was used to identify the MetAP2 gene from the human pathogenic microsporidia Encephalitozoon cuniculi, Encephalitozoon hellem, Encephalitozoon intestinalis, Brachiola algerae and E. bieneusi. The full-length MetAP2 coding sequence was obtained for all of the Encephalitozoonidae. Recombinant E. cuniculi MetAP2 was produced in baculovirus and purified using chromatographic techniques. The in vitro activity and effect of the inhibitors bestatin and TNP-470 on this recombinant microsporidian MetAP2 was characterized. An in silico model of E. cuniculi MetAP2 was developed based on crystallographic data on human MetAP2. These reagents provide new tools for the development of in vitro assay systems to screen candidate compounds for use as new therapeutic agents for the treatment of microsporidiosis.
\end{abstract}

The phylum Microsporidia is a group of obligate, intracellular, parasites containing over 1,100 species in at least 144 genera (Sprague et al. 1992, Wittner and Weiss 1999). These organisms are ubiquitous in nature, having been described as parasites in all classes of vertebrates (including most mammals) as well as in most invertebrates (Wittner and Weiss 1999, Deplazes et al. 2000). Within their hosts, most microsporidia infect the digestive tract, but reproductive, respiratory, muscle, excretory and nervous system infections also occur (Didier et al. 1991, 1996, Weber et al. 1997, 2000, Cali et al. 1998, Coyle et al. 2004). The Microsporidia are significant human and veterinary pathogens with impacts on medicine, agriculture and aquaculture. Human pathogenic microsporidia have been demonstrated in water supplies (Dowd et al. 1998).

These organisms are true eukaryotes containing a nucleus with a nuclear envelope, an intracytoplasmic membrane system, chromosome separation on mitotic spindles as well as Golgi apparatus (Takvorian and Cali 1994) and cryptic mitochondria (Williams et al. 2002). The small subunit rRNA genes of microsporidia are smaller than other eukaryotic rRNA genes and display prokaryotic features. This has led many investigators to conclude that they are phylogenetically very ancient protozoa. However, it is now commonly accepted that the microsporidia are not primitive organisms, but instead are degenerate protists related to fungi and that their divergent rRNA is due to evolutionary specialisation (Weiss et al. 1999, Keeling 2003). Microsporidian classification is currently based on observed spore ultrastructural features such as size, morphology and the number of coils of the polar tube; the developmental life cycle of the organism; and their hostparasite relationship (Sprague et al. 1992), however, molecular analysis has begun to alter this traditional classification system (Weiss 2000).

Several genera of microsporidia have been demonstrated in human disease: Nosema and Vittaforma (Silveira and Canning 1995), Pleistophora (Cali and Takvorian 2003), Encephalitozoon (Didier et al. 1991, Weber et al. 1997), Enterocytozoon (Desportes et al., 1985), Septata (now Encephalitozoon) (Cali et. al. 1993), Trachipleistophora (Field et al. 1996) and Brachiola (Cali et al. 1998, Coyle et al. 2004). Serosurveys have demonstrated a high prevalence of antibodies to microsporidia suggesting asymptomatic infection may

This paper was presented at the NATO Advanced Research Workshop "Emergent Pathogens in the 21st Century: First United Workshop on Microsporidia from Invertebrate and Vertebrate Hosts", held in České Budějovice, Czech Republic, July 12-15, 2004. 
be common (Hollister et al. 1991). Encephalitozoon hellem has been reported in cases of keratoconjunctivitis, sinusitis, respiratory disease, prostatic abscesses and disseminated infection; Encephalitozoon cuniculi in cases of hepatitis, encephalitis, and disseminated disease; and Encephalitozoon intestinalis in cases of diarrhoea, disseminated infection, and superficial keratoconjunctivitis (Didier et al. 1991, Cali et al. 1993, Weber et al. 1997, Wittner and Weiss 1999). Nosema, Vittaforma and Microsporidium have been reported in immunocompetent patients with stromal keratitis associated with trauma (Wittner and Weiss 1999). Pleistophora, Brachiola and Trachipleistophora have been reported in cases of myositis (Field et al. 1996, Cali et al. 1998, Coyle et al. 2004). Enterocytozoon bieneusi causes malabsorption, diarrhoea and cholangitis (Desportes et al. 1985). It is the most common cause of microsporidiosis in humans and it is now appreciated that it infects several other mammals and birds (Dengjel et al. 2001). The average prevalence of E. bieneusi infection in patients with HIV infection (AIDS) and chronic diarrhoea was $30 \%$ prior to the widespread use of highly active antiretroviral therapy (Wittner and Weiss 1999). Similar prevalence rates have been reported in children and patients with HIV infection in the developing world (Tumwine et al. 2002). Infection also occurs as a complication of organ transplantation (Rabodonirina et al. 2003) and has been reported in the elderly, travellers and immunocompetent hosts (Weber and Bryan 1994, Lores et al. 2002).

Two groups of therapeutic agents have been identified as being useful in the treatment of human microsporidiosis (Costa and Weiss 2000). The benzimidazoles, which bind tubulin, include albendazole, the benzimidazole of choice for treatment of microsporidio-sis due to the Encephalitozoonidae (Costa and Weiss 2000). These drugs, however, are not effective for the treatment of microsporidiosis due to E. bieneusi (Dieterich et al. 1994, Katiyar et al. 1994). The second group of compounds is fumagillin and its derivatives. It has been recognized for several years that fumagillin, an antibiotic derived from fungi, has activity against sev-eral groups of parasites (Katsnelson and Jamieson 1952, Shadduck 1980, Rosberger et al. 1993). It is used for the treatment of nosematosis, a microsporidiosis of honeybees, and was utilized to treat Entamoeba histolytica prior to the development of more effective amebicides (Katsnelson and Jamieson 1952). Several laboratories have demonstrated in vitro that this drug has activity against both Encephalitozoonidae and Vittaforma corneae (Shadduck 1980, Franssen et al. 1995, Didier 1997, Coyle et al. 1998). TNP-470, a fumagillin derivative developed as an anti-angiogenesis drug, is active both in vitro and in vivo against several microsporidia (Coyle et al. 1998, Higgins et al. 1998). Fumagillin has been demonstrated to have efficacy for the treatment of diarrhoea due to E. bieneusi in AIDS patients (Molina et al. 2002). A dose of $60 \mathrm{mg} / \mathrm{d}$ of fumagillin cleared $E$. bieneusi from the stool of 8 of $11(72 \%)$ of treated patients and was associated with the clinical resolution of disease (as assessed by elimination of diarrhoea and weight gain) (Molina et al. 2002). Fumagillin did, however, cause thrombocytopaenia in these patients, although this side effect did not limit these clinical trials (Molina et al. 2002).

TNP-470 and ovalicin have been demonstrated to bind irreversibly to a common bifunctional protein identified by mass spectrometry as methionine aminopeptidase type 2 (MetAP2) (Griffith et al. 1997, Sin et al. 1997). In yeasts and higher eukaryotes two isoforms (type 1 and type 2) of MetAP exist. These drugs do not bind or inhibit the activity of methionine aminopeptidase type 1 (MetAP1) or other aminopeptidases. A $1.8 \AA$ resolution crystal structure of free and inhibited human MetAP2 demonstrated that a covalent bond is formed between a reactive epoxide of fumagillin and histidine $_{231}$ (human MetAP2) in the active site of MetAP2 (Liu et al. 1998). This crystal structure demonstrated the extensive hydrophobic and water-mediated interactions that provide the selective affinity of fumagillin for MetAP2 over MetAP1 (Liu et al. 1998). Studies have demonstrated that fumagillin derivatives display tissueand species selectivity in their ability to inhibit MetAP2 (Turk et al. 1998), suggesting that it should be possible to design selective MetAP2 inhibitors. Saccharomyces cerevisiae deficient in MetAP1 (i.e. mapl yeasts dependent on MetAP2) are killed by ovalicin, but yeasts deficient in MetAP2 (map2 yeasts dependent on MetAP1) are not (Griffith et al. 1997, Sin et al. 1997). Deletion of both MetAP1 and MetAP2 is lethal. This confirms that fumagillin selectively targets MetAP2 and not MetAP1. Removal of the terminal methionine of a protein is often critical for function and post-translational modification of a protein.

Our data (Weiss et al. 2001, 2003) as well as that of other groups (Millership et al. 2002, Didier et al. 2003) indicate that the cellular target for fumagillin and its analogues in the Microsporidia is a microsporidian MetAP2 homologue and that this is an essential enzyme for these organisms. The microsporidium Encephalitozoon cuniculi lacks MetAP1 based on the published $E$. cuniculi genome (Katinka et al. 2001); therefore, inhibition of MetAP2 by fumagillin most likely results in cell death, analogous to the situation in mapl yeast. Studies were, therefore, undertaken to clone and characterize the MetAP2 of several of the Microsporidia, in order to produce reagents that would facilitate the development of more selective MetAP2 inhibitors for the treatment of microsporidiosis.

\section{MATERIALS AND METHODS}

Microsporidia culture, purification and DNA preparation. E. cuniculi, E. hellem and B. algerae were cultivated in rabbit kidney cells (RK-13) using MEM containing 7\% FBS 
as previously described (Keohane et al. 1996, 1998, Coyle et al. 2004). Seven to ten days after infection of near confluent RK-13 cells, in T75 flasks, spores were harvested from the medium. Spores of Glugea americanus (Takvorian et Cali, 1986) [recently reclassified as Spraguea americanus (Freeman et al. 2004)] were purified from cysts found in the cranial and spinal ganglia of the angler fish, Lophius americanus, and were stored at $4{ }^{\circ} \mathrm{C}$ in sea water as previously described (Keohane et al. 1996). Microsporidian spores were purified by filtration through nucleopore filters, treated with $0.2 \%$ SDS for $20 \mathrm{~min}$, washed with PBS and resuspended in proteinase $\mathrm{K}$ buffer $[10 \mathrm{mM} \mathrm{pH} 7.5$ Tris $\mathrm{HCl}, 10 \mathrm{mM}$ EDTA, $150 \mathrm{mM}$ $\mathrm{NaCl}, 0.4 \%$ SDS] . Purified spores were then disrupted using acid-washed $500-\mu \mathrm{m}$ glass beads in a Mini-Bead beater (Biospec Products Inc., Bartlesville, OK). Proteinase K was added to the disrupted spores and the solution was incubated for 15 min at $65^{\circ} \mathrm{C}$. DNA was then prepared by phenol/chloroform extraction followed by ethanol precipitation. Purified microsporidian DNA was dissolved in TE buffer and stored at $-20^{\circ}$ C. Enterocytozoon bieneusi DNA (gift of Dr. Saul Tzipori, Tufts University, School of Veterinary Medicine) was prepared from purified spores (purity confirmed by transmission electron microscopy) isolated from human faeces (cases were confirmed by PCR with specific primers to the $E$. bieneusi small subunit rRNA gene) (Sheoran et al. 2005).

Identification of microsporidian MetAP2 genes. To obtain the microsporidian MetAP2 genes a strategy of homology cloning using the polymerase chain reaction (PCR) and degenerate primers to areas of conservation between yeast and mammalian MetAP2 genes (Weiss et al. 2001, 2003) was employed. Primer pairs M1 [D(A/V)(R/L)VCDIG] 5'GAY GYIMIBTITGYGAYATIGG3'::M3-[KVAQFEHT] 5'GTR TGYTCRAAYTGIGCIACYTT3', and M2 [QFKIHGG] 5'CARTTYAARATHCAYGGIGG5':: M4 [RGDDY] 5'ARA TRTCRTCICCICG3' were designed based on an alignment of the human, mouse, and Saccharomyces MetAP2 genes with a partial E. hellem MetAP2 homologue that we had previously obtained by homology PCR (Weiss et al. 2001, 2003) and a partial MetAP2 homologue identified in a gene sequence survey (GSS) of the microsporidium Glugea americanus [Spraguea lophii gene sequence survey, Dr. M. Sogin, Marine Biological Laboratory, Woods Hole, MA, http//evol3.mbl.edu/ Spraguea] (Takvorian and Cali 1986). The primer set M2::M4 amplifies the conserved $\mathrm{C}$ terminal region of MetAP2. PCR was performed using a Perkin Elmer 2400 PCR machine (Perkin Elmer Corporation, Foster City, CA) employing a $10 \mathrm{~min}$ $95^{\circ} \mathrm{C}$ cycle followed by 35 cycles of $95^{\circ} \mathrm{C}$ for $1 \mathrm{~min}, 48^{\circ} \mathrm{C}$ for $1 \mathrm{~min}$ and $72^{\circ} \mathrm{C}$ for $1 \mathrm{~min}$. This was followed by $7 \mathrm{~min}$ of $72^{\circ} \mathrm{C}$ and the reactions were then stored at $4^{\circ} \mathrm{C}$. Amplicons of the expected size were obtained using M1::M3 and M2::M4 from Brachiola algerae (Ba), Glugea americanus $(\mathrm{Ga})$, Encephalitozoon intestinalis (Ei), Encephalitozoon cuniculi (Ec), Encephalitozoon hellem (Eh), and Enterocytozoon bieneusi (Eb). These amplicons were then subcloned into PCR 2.1, a TA cloning vector (Invitrogen, Carlsbad, CA). A total of 3 clones from each amplicon was sequenced on an ABI Prism Model 377 DNA Sequencer (Perkin Elmer Corporation, Foster City, CA) using T7 and M13 primers flanking the insertion site as well as additional 18 to $20 \mathrm{bp}$ oligomers selected using Oligo Primer Analysis Software (NBI, Plymouth, MN) based on the observed sequence data. Sequence data sets were assembled using the SeqMan program of the LaserGene Software Package (DNASTAR, Madison, WI). DNA and protein homology was examined with BLAST (http://www.ncbi. nlm.nib.gov/blast/), protein motifs with PROSITE (GCG Version 8.0, Madison, WI) and phylogenetic analysis was performed using MegAlign (DNASTAR, Madison, WI).

To obtain full-length microsporidian MetAP2 gene sequences 5'random amplification of cDNA ends (RACE) primers were designed to obtain the amino-terminus and 3'RACE primers to confirm the carboxy-terminus of the E. hellem and $E$. intestinalis MetAP2 gene as we previously described for $E$. cuniculi (Weiss L.M. and Zhang H., Woods Hole Molecular Parasitology Meeting XIII, 2002, 284A, Weiss et al. 2003). Primers were designed so that they would not amplify mammalian MetAP2. The TRIzol method (Invitrogen, Carlsbad, CA) was used to prepare RNA from E. hellem and E. Intestinalis cultured in RK-13 in order to obtain mRNA from proliferating forms. Control RNA was also prepared from uninfected RK-13 using the same technique. 5'RACE and 3'RACE PCR was carried out using standard techniques per the manufacturer's protocol (Invitrogen, Carlsbad, CA). A nested primer employed technique was used for the 5'RACE for $E$. hellem using primers EH5A: 5'CGACGGTTTCTGTAC CTTCTTTG3' and EH5B: 5'TCAGCAGAGGCTCGAAC TCCTCCTTG3' and for E. intestinalis using primers EI5A: 5'CGATGAAGGGGAGCATGGAG3' and EI5B: 5'CGTGTC TCCCTTGATTCTTGTTG3'. A nested primer technique was also used for 3'RACE for $E$. intestinalis employing primers EI3A: 5'GTGCACAAGAGCAGGAAGCTC3' and EI3B 5'CACTACAACCTGGTTGAGG3'. For the 3'RACE of $E$. hellem only a single primer EH3: 5'CGACACACAAGA GCAGAAAG3' was required. These microsporidian MetAP2 specific primers did not amplify anything from RNA prepared from uninfected RK-13 cells. Amplicons were then subcloned into PCR 2.1, a TA cloning vector (Invitrogen, Carlsbad, CA) and 3 clones from each amplicon were sequenced on an $\mathrm{ABI}$ Prism Model 377 DNA Sequencer (Perkin Elmer Corporation, Foster City, CA) using T7 and M13 primers flanking the insertion site as well as additional 18 to $20 \mathrm{bp}$ oligomers selected using Oligo Primer Analysis Software (NBI, Plymouth, $\mathrm{MN}$ ) based on the observed sequence data. Sequence data sets were assembled using the SeqMan program of the LaserGene Software Package (DNASTAR, Madison, WI).

GenBank accession numbers. The full-length MetAP2 sequences from E. cuniculi (AF440270), E. intestinalis (AY224693) and E. hellem (AY224694) were deposited in GenBank.

Expression and purification of recombinant EcMetAP2 (rEcMetAP2). Primers (EcM2Bgl2F: 5'GAAGATCTGTGA ATGGATAATTCTCCA3' and EcM2EcoR1R: 5'CAGAAT TCGTCTTTAATAGTCATCGCC3') designed to provide $B g l I I$ and $E c o R 1$ sites flanking the EcMetAP2 gene were used with Pfu polymerase to clone EcMetAP2 into PCR2.1-TOPO (Invitrogen, Carlsbad, CA) and the EcMetAP2 sequence verified. The $B g / I I / E c o R 1$ insert was excised and cloned into the baculovirus vector pVL1392 that had been digested with $B g l I I / E c o R 1$. The pVL1392:EcMetAP2 construct was then expressed in Sf9 insect cells employing the BakPAK Baculovirus expression system (BD Biosciences CloneTech, Palo 
Alto, CA). Five days post infection with pVL1392:EcMetAP2 the Sf9 were harvested from $100 \times 20 \mathrm{~mm}$ culture plates and centrifuged at $1,200 \times g$ for $5 \mathrm{~min}$. The supernatant was dialyzed against $10 \mathrm{mM} \mathrm{pH} 7.5 \mathrm{Tris} \mathrm{HCl}$ and then concentrated by centrifugation employing a Centricon-30 concentrator (Milipore, Billerica, MA). rEcMetAP2 was then purified from the supernatant by Fast Protein Liquid Chromatography (FPLC) employing either (1) Pharmacia FPLC with a UNO ${ }^{\mathrm{TM}}$ Q12 column (BioRad, Hercules, CA) employing a $0.5 \mathrm{ml} / \mathrm{min}$, $30 \mathrm{~min}$, linear 0 to $1 \mathrm{M} \mathrm{NaCl}$ gradient in $20 \mathrm{mM}$ Tris $\mathrm{HCl} \mathrm{pH}$ 7.5 or (2) an AKTA FPLC with a Superose 6 HR 10/30 column employing a $0.3 \mathrm{ml} / \mathrm{min}$ flow rate of $20 \mathrm{mM} \mathrm{pH} 7.5$ Tris $\mathrm{HCl}$. Fractions were collected every minute and the presence of rEcMetAP2 was determined by immunoblot. Fractions containing immunoreactive EcMetAP2 were assayed for MetAP2 enzyme activity.

Production of polyclonal anti-rEcMetAP2. As previously published (Weiss et al. 2001, 2003), rEcMetAP2 purified by FPLC using a UNO ${ }^{\mathrm{TM}}$ Q12 column (BioRad, Hercules, CA) employing a $0.5 \mathrm{ml} / \mathrm{min}, 30 \mathrm{~min}$, linear 0 to $1 \mathrm{M} \mathrm{NaCl}$ gradient in $20 \mathrm{mM} \mathrm{pH} 7.5 \mathrm{Tris} \mathrm{HCl}$ was reactive on immunoblot with a polyclonal rabbit antibody to the recombinant catalytic domain of human MetAP2 [anti-cHuMetAP2] (Zymed Laboratories, San Francisco, CA) and had MetAP2 activity by enzyme assay. SDS-PAGE was used to purify this reactive protein band $(\sim 40 \mathrm{kDa})$ corresponding to rEcMetAP2. This protein band was then used to immunize three CD-1 mice ( $3 \mu \mathrm{g}$ protein per mouse) employing Hunters TiterMax ${ }^{\mathrm{TM}}$ as an adjuvant. Mice were bled at 4, 8, and 12 weeks and sera examined by immunoblot.

Immunoblot. Microsporidian spore lysate or FPLCpurified proteins were resolved by SDS-PAGE $(10 \%$ polyacrylamide), electroblotted to nitrocellulose and incubated with a 1:1,000 dilution of anti-cHuMetAP2 or a 1:2,500 dilution of anti-rEcMetAP2. Immune complexes were visualised using a 1:5,000 dilution of anti-rabbit IgG (for anticHuMetAP2) or anti-mouse IgG (for anti-rEcMetAP2) alkaline phosphatase-conjugated secondary antibody (Tropix Inc., Bedford, MA) and either a chemoluminescent detection system using CSPD* (Western Light, Tropix, Inc., Bedford, MA) or BCIP/NBP [5-bromo-4-chloro-3-indolyl-phosphate/nitro blue tetrazolium] (Promega, Madison, WI).

In vitro assay for MetAP2 activity. Activity was evaluated with two different assays. The MetAP2 substrate methionine-para-nitroanilide was used to evaluate the presence of MetAP2 activity in microsporidian spore lysate (Chang et al. 1990; Li and Chang 1995). Spore lysates were prepared by disrupting $250 \mu \mathrm{l}$ of E. cuniculi or E. hellem spores $\left(10^{8}\right.$ spores $/ \mathrm{ml}$ ) in PBS at $4^{\circ} \mathrm{C}$ in a Mini-Beadbeater using $500-\mu \mathrm{m}$ acid-washed glass beads. Bestatin $(2 \mu \mathrm{g} / \mathrm{ml})$, TNP-470 (100 $\mu \mathrm{g} / \mathrm{ml}$ ), or DMSO were added to the lysate $30 \mathrm{~min}$ before adding the lysate to reaction buffer (20 mM Hepes, $\mathrm{pH} 7.5,40$ $\mathrm{mM} \mathrm{KCl}, 4 \mathrm{mM}$ methionine-para-nitroanilide) in the presence and absence of $1.5 \mathrm{mM} \mathrm{CoCl}_{2}$. The reaction was monitored at $405 \mathrm{~nm}$ for $4 \mathrm{~h}$.

MetAP2 activity was also assessed using the Met-Pro- $p$ nitroanilide assay published by Zhou (Zhou et al. 2000). The assay was carried out at room temperature using $160 \mu \mathrm{l}$ of reaction buffer $(50 \mathrm{mM}$ MOPS pH 7.0, $10 \mathrm{mM} \mathrm{NaCl}, 100 \mu \mathrm{M}$ $\mathrm{CoCl}_{2}, 0.5 \mathrm{mM}$ Met-Pro-pNA and $1.0 \mathrm{unit} / \mathrm{ml}$ of ProAP from
Bacillus coagulans) and $10 \mu 1$ of purified rEcMetAP2 or rEcMetAP2 with inhibitor (either TNP-470 or bestatin). The reaction was continuously monitored at $405 \mathrm{~nm}$ using an UVVIS spectrophotometer.

In silico analysis of EcMetAP2. MODELLER (Insight II version 2000.1, Accelrys Inc.) (Sali and Overington 1994) was used to overlay the EcMetAP2 gene sequence with the published crystal structure of free and complexed human methionine aminopeptidase type 2 (1BN5 of HuMetAP2 and 1BOA of HuMetAP2-fumagillin) (Liu et al. 1998) using a SUN workstation. The sequences were aligned using the ALIGN3D routine of MODELLER. Alignment was evaluated and refined by visual inspection of the model.

\section{RESULTS}

We had previously reported that microsporidian spores have aminopeptidase activity and identified the MetAP2 gene from E. cuniculi and E. hellem (Weiss et al. 2001, 2003). The M2::M4 primer set was used to obtain the MetAP2 genes by homology PCR employing DNA purified from the following microsporidia: Brachiola algerae (Ba), Glugea americanus (Ga), Encephalitozoon intestinalis (Ei), Encephalitozoon cuniculi (Ec), Encephalitozoon hellem (Eh), and Enterocytozoon bieneusi $(\mathrm{Eb})$. As demonstrated in Fig. 1, amplicons of the appropriate size were seen from all of these microsporidia. Analysis of the sequence of these amplicons using BLASTX and BLASTP confirmed that these were microsporidian MetAP2 genes (blast scores $>150$ compared to other eukaryotic MetAP2 genes and $>200$ compared to E. cuniculi MetAP2) and that they contained a Map domain (COG0024.1, methionine aminopeptidase).

The full-length MetAP2 genes of E. hellem and E. intestinalis were obtained by 5' and 3' RACE as we had previously reported for E. cuniculi (Weiss L.M. and Zhang H., Woods Hole Molecular Parasitology Meeting XIII, 2002, 284A; Weiss et al. 2003). As noted in genes reported from E. cuniculi by other groups the 5'UTR was almost non-existent consisting of only a few bp preceding the initial ATG. Comparison with human MetAP2 (NP006829) demonstrates that the encephalitozoonid MetAP2 genes contain all of the conserved residues (R1 through R5) seen in other eukaryotic MetAP2 genes, which are associated with the catalytic domain. Residues R1 through R5, D-D-H-E-E, are indicated by bold text in Fig. 2 and are the residues involved in binding the two metal ions required for the catalytic site of MetAP2. The $\mathrm{His}_{231}$ residue (human MetAP2 numbering) where the spiro-epoxide of fumagillin forms a covalent bond with MetAP2 is also present in the microsporidian MetAP sequences (see shaded residue, Fig. 2). The locations of primers M1 through M4 are indicated by underlined text in the E. hellem MetAP2 sequence. The microsporidian MetAP2s also contain the characteristic carboxyl insertion that is present in MetAP2 and absent in MetAP1 (Taylor1993). All of the 

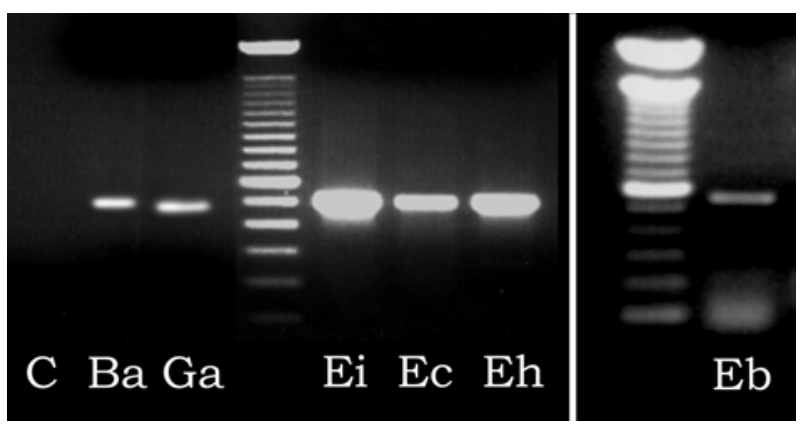

Fig. 1. Polymerase chain reaction using primers M2::M4 of microsporidian DNA demonstrating the presence of microsporidian MetAP2 amplicons. The $\sim 500$ bp amplicons are consistent with the predicted size of a MetAP2 amplicon based on the location of these primers in other eukaryotic MetAP2 sequences. A $100 \mathrm{bp}$ ladder is used as the molecular weight standard. C - control with no DNA. Ba - Brachiola algerae, $\mathrm{Ga}$ - Glugea americanus, Ei - Encephalitozoon intestinalis, Ec - Encephalitozoon cuniculi, Eh - Encephalitozoon hellem, $\mathrm{Eb}$ - Enterocytozoon bieneusi.

microsporidian MetAP2 genes lack the N-terminal polylysine region associated with the interaction of MetAP2 and p67, which is present in all other eukaryotic MetAP2s.

Using the MegAlign program (LaserGene), Clustal_W was used to generate a phylogeny of the MetAP $\overline{2}$ protein sequences of the microsporidia $B$. algerae, G. americanus, E. cuniculi (AF440270), E. intestinalis (AY224693), E. hellem (AY224694), and E. bieneusi with other eukaryotic MetAP2s from Xenopus laevis (AAH43889), Schizosaccharomyces pombe (NP595 906), Saccharomyces cerevisiae (CSS84913), Rattus norvegicus (AAH70892), Plasmodium yoelii (EAA 22023), Plasmodium falciparum (NP702216), Neurospora crassa (CAD71035), Mus musculus (AAH02 213), Homo sapiens (NP006829), Giardia lamblia (EAA39272), Drosophila melanogaster (AAC05144), Danio rerio (NP955934), Cryptosporidium parvum (EAK88752), Aspergillus nidulans (EAA60321), Arabidopsis thaliana (AAG34551); the MetAP1 from Homo sapiens (NP055958); the MAP (Peptidase M) from the Eubacteria, Escherichia coli (PO7906); and archaean MAPs (Peptidase M) from Sulfolobus solfataricus P2 (AAK40454), Pyrococcus horikoshii (NP 1490519), Methanococcus maripaludis S2 (NP988564), Methanothermobacter thermautotrophicus (NP276415). As can be seen in Fig. 3, the microsporidian MetAP2s are most closely related to other eukaryotic MetAP2s and not to MetAP1 or bacterial MAPs. However, the microsporidian MetAP2s form a clade that is distinct from other eukaryotic MetAPs and that does not root with the fungi included in this analysis. The encephalitozoonid MetAP2s are more closely related to each other than to the other micro- sporidian MetAP2s. Eukaryotic MetAP2 is related to archaean MAP and eukaryotic MetAP1 to eubacterial MAP, as has been demonstrated by other groups (Keeling and Doolittle 1996, Lowther and Matthews 2000).

As demonstrated in Fig. 4A, antibody to the catalytic subunit of human MetAP2 (anti-Hu-cMetAP2) reacted with spore lysates from E. cuniculi (Weiss et al. 2003). Recombinant E. cuniculi MetAP2 (rEcMetAP2) was successfully expressed using a baculovirus expression system and this rEcMetAP2 also reacted with anti-HucMetAP2 (Figure 4A). Antibody was produced to rEcMetAP2 purified by FPLC using a $\mathrm{UNO}^{\mathrm{TM}} \mathrm{Q} 12$ column and this antibody reacted with the same band recognized by anti-Hu-cMetAP2 in spore lysate (Fig. 4B) as well as with rEcMetAP2 (Fig. 4B).

Enzymatic activity consistent with MetAP2 was present in rEcMetAP2 purified by FPLC using either a $\mathrm{UNO}^{\mathrm{TM}} \mathrm{Q} 12$ or a Sepharose $6 \mathrm{HR} 10 / 30$ column. As demonstrated in Fig. 5, FPLC using Sepharose 6 HR $10 / 30$ produced a peak that on SDS-PAGE had a single band of $\sim 40 \mathrm{kDa}$ that was reactive with anti-rEcMetAP2 (Fig. 5, insert panel). This purified rEcMetAP2 had an enzymatic activity that was maximal at $\mathrm{pH} 6.5$ (Fig. 6A). Fig. 6B demonstrates that $2 \mu \mathrm{g} / \mathrm{ml}$ of bestatin inhibited the rEcMetAP2 in $10 \mu \mathrm{l}$ of purified enzyme about as well as $0.1 \mu \mathrm{g} / \mathrm{ml}$ of TNP-470 and that $20 \mu \mathrm{g} / \mathrm{ml}$ of bestatin further inhibited this enzyme. However, $10 \mu \mathrm{g} / \mathrm{ml}$ of TNP-470 (as well as $1 \mu \mathrm{g} / \mathrm{ml}$, data not shown) completely and irreversibly eliminated all rEcMetAP2 activity in 10 $\mu l$ of purified enzyme. Bestatin is an inhibitor of metaloproteases and TNP-470 is a specific irreversible inhibitor of MetAP2.

\section{DISCUSSION}

Several laboratory groups have demonstrated that fumagillin, ovalicin and fumagillin analogues, e.g. TNP470 and FOS68, inhibit the in vitro growth of Encephalitozoon hellem, E. cuniculi, E. intestinalis and other microsporidia at concentrations as low as $3 \mathrm{nM}$ (Didier 1997, Didier et al. 1998, Coyle et al. 1998, Weiss et al. 2001). In addition, both fumagillin and TNP-470 have demonstrated activity in murine and fish models of microsporidiosis (Coyle et al. 1998, Higgins et al. 1998). Fumagillin has also been demonstrated to have efficacy in human infection with $E$. hellem (ocular disease) and E. bieneusi (intestinal disease) (Molina et al. 2002). The activity of these drugs is due to their ability to bind to MetAP2 via an epoxide ring that is the site of their covalent binding to a histidine residue in the active site of MetAP2 (Griffith et al. 1997, Sin et al. 1997). FOS67, which has an open epoxide ring, has minimal antimicrosporidial activity at $30 \mathrm{nM}$, consistent with the target of these compounds being MetAP2 in the Microsporidia (Weiss et al. 2001). We had previously reported that spore lysates from both E. cuniculi and $E$. hellem had methionine aminopeptidase activity that 


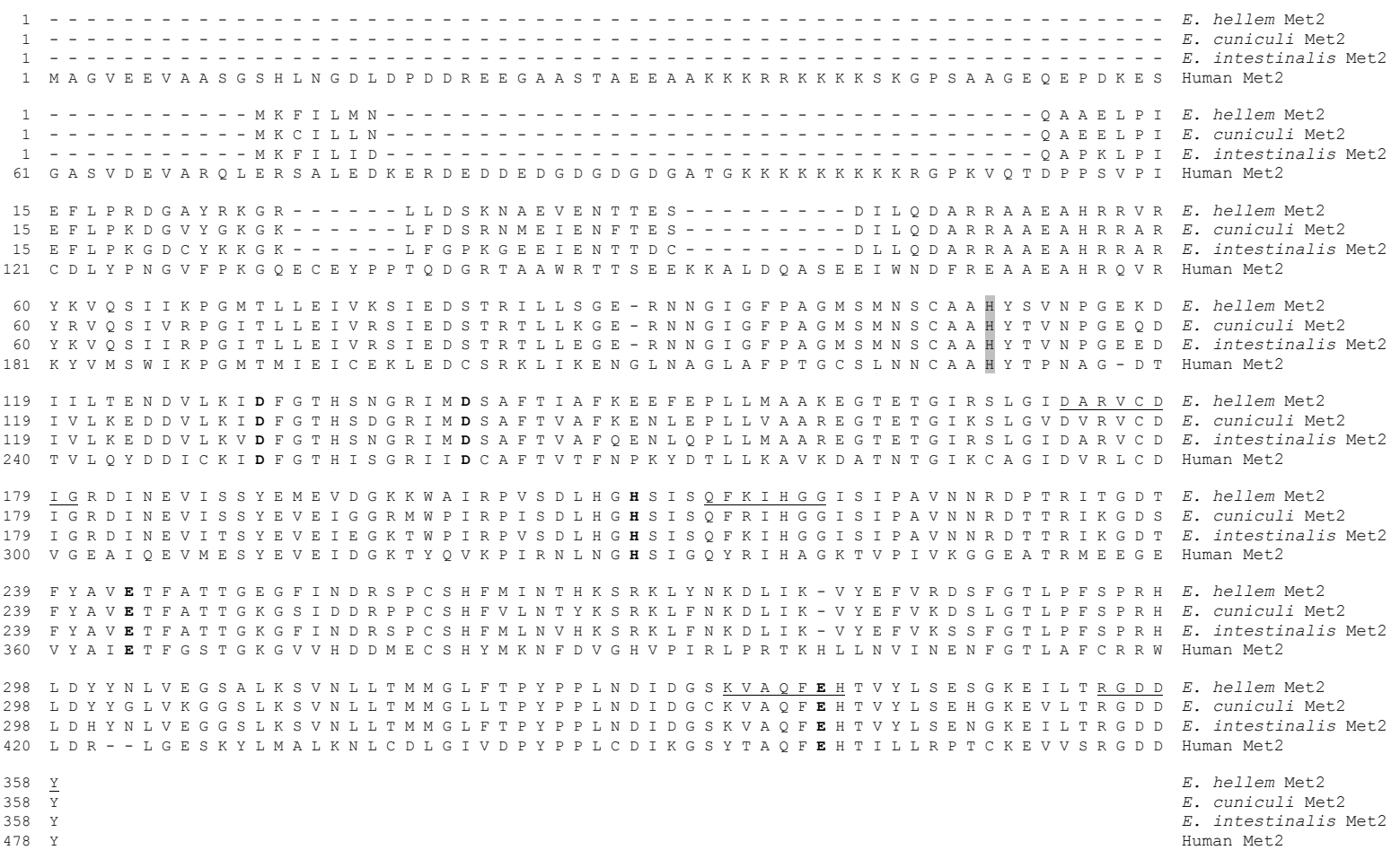

Fig. 2. Alignment (Clustal W) of full-length microsporidian methionine aminopeptidase type 2 with human methionine aminopeptidase type 2. Microsporidia: Encephalitozoon cuniculi (AF440270), E. intestinalis (AY224693), and E. hellem (AY224694); human: Homo sapiens (NP006829). The amino acids D-D-H-E-E indicated by bold text are involved in binding the two metal ions required for the catalytic site. The locations of primers M1 through M4 are indicated by underlined text. The shaded residue is the histidine where the spiro-epoxide of fumagillin is predicted to form a covalent bond with MetAP2.

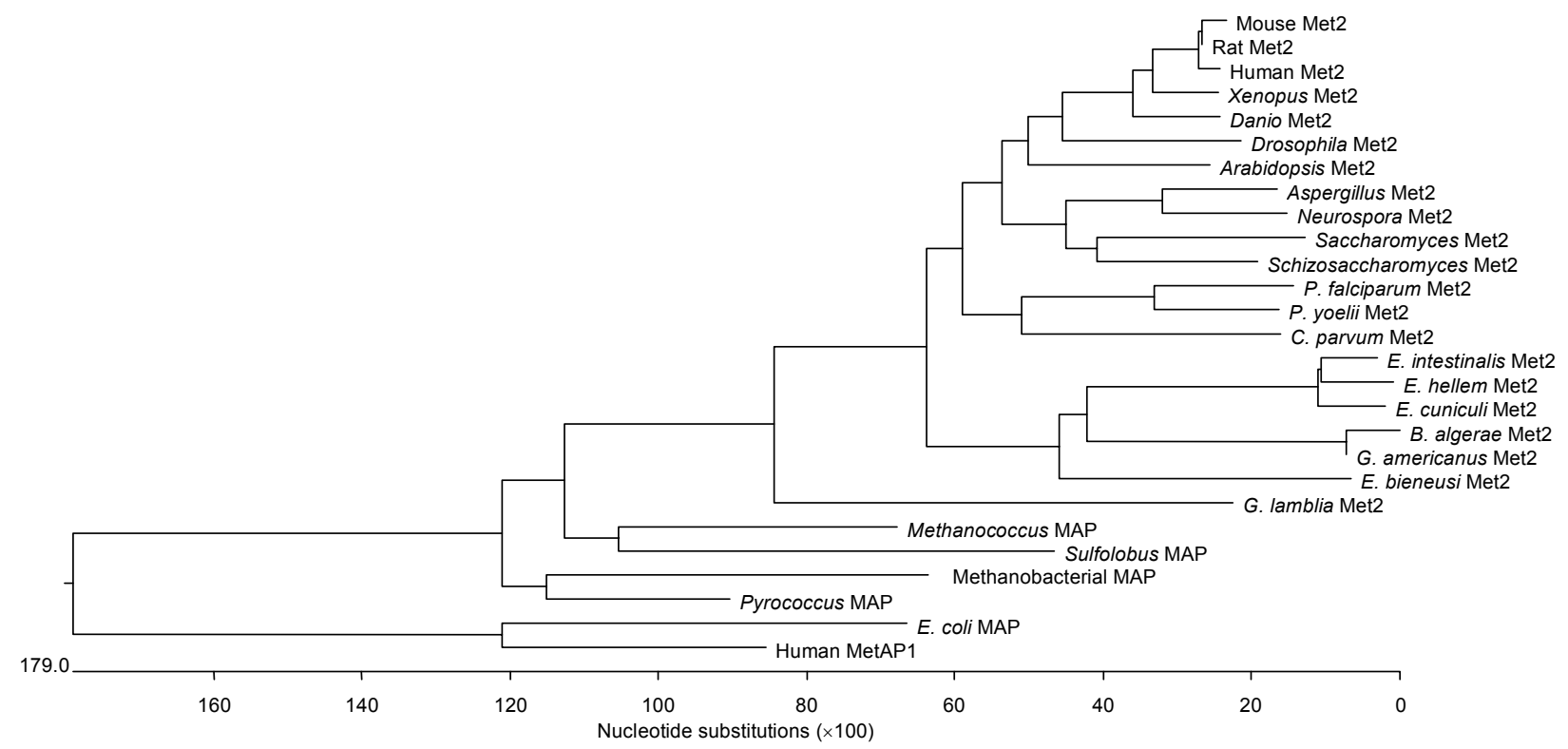

Fig. 3. Clustal_W analysis of MetAP2, MetAP1 and MAP proteins using MegAlign (DNASTAR). MetAP2: Xenopus Met2 (Xenopus laevis), Schizosaccharomyces Met2 (Schizosaccharomyces pombe), Saccharomyces Met2 (Saccharomyces cerevisiae), Rat Met2 (Rattus norvegicus), P. yoelii Met2 (Plasmodium yoelii), P. falciparum Met2 (Plasmodium falciparum), Neurospora Met2 (Neurospora crassa), Mouse Met2 (Mus musculus), Human Met2 (Homo sapiens), G. lamblia Met2 (Giardia lamblia), Drosophila Met2 (Drosophila melanogaster), Danio Met2 (Danio rerio), C. parvum Met2 (Cryptosporidium parvum), Aspergillus Met2 (Aspergillus nidulans), Arabidopsis Met2 (Arabidopsis thaliana), B. algerae Met2 (Brachiola algerae), G. americanus Met2 (Glugea americanus), E. cuniculi Met2 (Encephalitozoon cuniculi), E. intestinalis Met2 (Encephalitozoon intestinalis), E. hellem Met2 (Encephalitozoon hellem), and E. bieneusi Met2 (Enterocytozoon bieneusi). MetAP1: Homo sapiens. MAP (Peptidase M) Eubacteria: E. coli MAP (Escherichia coli). MAP (Peptidase M) Archaea: Sulfolobus MAP (Sulfolobus solfataricus P2), Pyrococcus MAP (Pyrococcus horikoshii), Methanococcus MAP (Methanococcus maripaludis S2), Methanobacterial MAP (Methanothermobacter thermautotrophicus). 


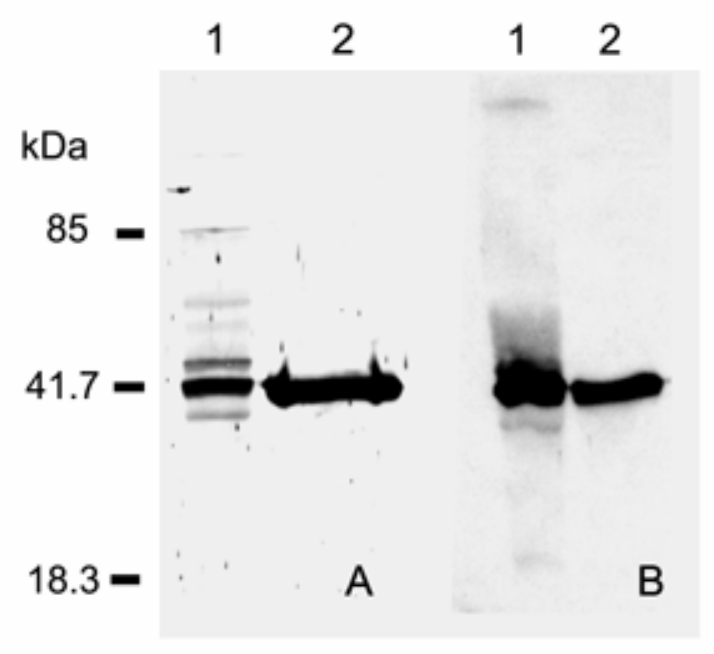

Fig. 4. Reactivity of native and recombinant microsporidian MetAP2 with antibodies to human and Encephalitozoon MetAP2. A. Immunoblot using anti-cHuMetAP2. This antibody reacted with a $\sim 40-\mathrm{kDa}$ protein in Encephalitozoon cuniculi spore lysates (lane 1) and to rEcMetAP2 expressed in Sf9 cells (lane 2). No reactivity was seen in Sf9 cells without the PVL1392-EcMetAP2 construct (data not shown). B. Immunoblot using anti-rEcMetAP2. This anti-rEcMetAP2 reacted with a $\sim 40-\mathrm{kDa}$ protein in E. cuniculi spore lysates (lane 1) and to rEcMetAP2 expressed in Sf9 cells (lane 2). No reactivity was seen in Sf9 cells without PVL1392-EcMetAP2 (data not shown). (Reprinted with permission from Weiss et al. 2003.)

could be inhibited by bestatin or TNP-470. Using Lmethionine-AFC, but not Z-methionine-AFC, a band could be visualised in non-denaturing gels of spore lysates, consistent with the presence of methionine aminopeptidase in the Microsporidia (Weiss et al. 2001). These data are consistent with the presence of methionine aminopeptidase type 2 in the Microsporidia and that inhibition of MetAP2 is a viable therapeutic approach for the treatment of microsporidiosis.

We, therefore, developed homology PCR techniques for the identification of MetAP2 genes in the Microsporidia and used these techniques to successfully obtain the MetAP2 genes from several of the Microsporidia. BLAST and phylogenetic analysis confirmed that the Microsporidia contain MetAP2 genes. These genes differ from other eukaryotic MetAP2s by the absence of an $\mathrm{N}$-terminal domain (poly-lysine rich region) that interacts with the alpha subunit of initiation factor-2 ( $\mathrm{Li}$ and Chang 1996), however, this does not affect the enzyme activity of MetAP2 (Figs. 3, 7). This N-terminal extension is not associated with MetAP2 activity and is lacking in archaean MetAP2 genes (e.g. Pyrococcus furiosus) (Taylor 1993). The loss of this extension in EcMetAP2 is consistent with the reduction in gene size and "simplification" of genes seen in other microsporidian genes (Katinka et al. 2001, Slamovits et al. 2004). It is clear that one can design microsporidian specific primers for

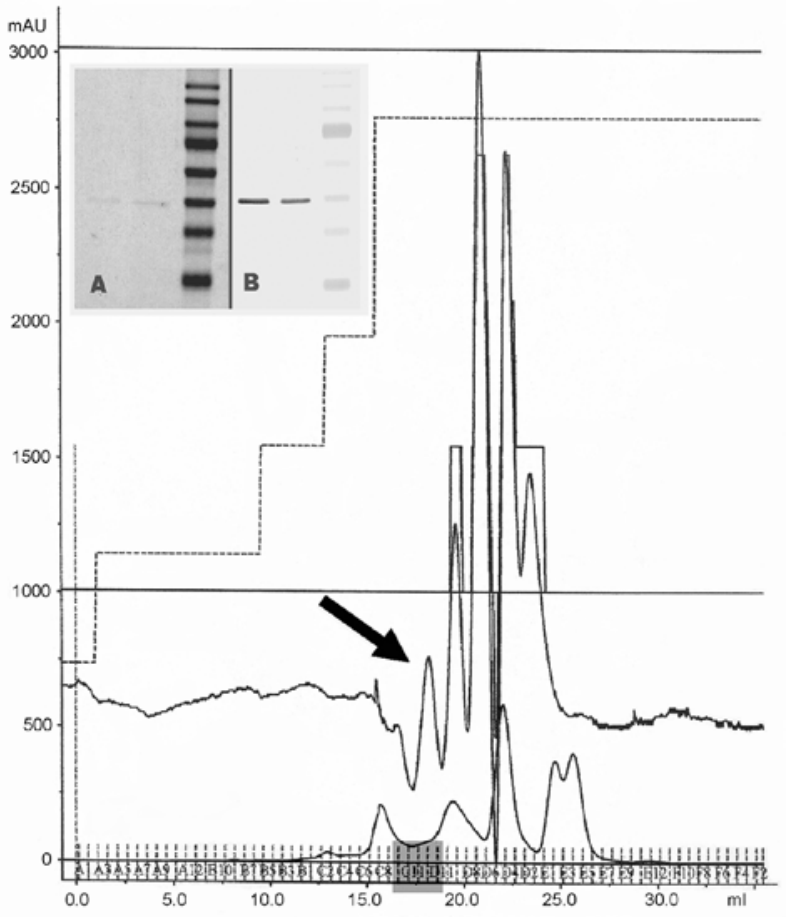

Fig. 5. Purification of recombinant Encephalitozoon cuniculi methionine aminopeptidase type 2 (rEcMetAP2). An AKTA prime FPLC employing a Sepharose 6 column was used to isolate rEcMetAP2 produced from baculovirus (PVL1392EcMetAP2) infected Sf9 cells. The arrow points to peak from the fractions corresponding to EcMetAP2. Insert A: Coomassie blue stain of SDS-PAGE demonstrating a single protein of expected size in this peak. Insert B: Immunoblot using antiEcMetAP2 demonstrating reactivity of the purified protein with antibody to EcMetAP2.

MetAP2. The sequence alignment of microsporidian MetAP2s with that of other eukaryotic MetAP2s demonstrates that the microsporidian MetAP2s form a separate clade. While the Microsporidia are related to fungi, their MetAP2 genes did not demonstrate any stronger relationship to fungal MetAP2 than to that of other eukaryotes.

Analysis of EcMetAP2 demonstrated conservation of the key residues associated with the active site of this class of enzymes including (numbers refer to the human MetAP2 sequence) $\mathrm{Asp}^{251}, \mathrm{Asp}^{262}, \mathrm{His}^{331}, \mathrm{Glu}^{364}$ and $\mathrm{Glu}^{459}$ (involved in coordination of metal binding); $\mathrm{His}^{231}$ (to which fumagillin covalently binds); and $\mathrm{Phe}^{219}$, $\mathrm{Leu}^{328}, \mathrm{Ile}^{338}, \mathrm{His}^{339}, \mathrm{Asp}^{378}, \mathrm{Tyr}^{444}, \mathrm{Leu}^{447}$ (involved in binding substrates into the active site) (Liu et al. 1998). Like all other eukaryotic MetAP2 genes it has a Cterminal insertion that is not present in methionine aminopeptidase type 1 (MetAP1) genes (Taylor 1993). Analysis of a structural model of EcMetAP2 demonstrated that its active site can be superimposed on the human MetAP2 model (Fig. 7) suggesting the active sites of both MetAP2 proteins are likely identical. There are, however, differences in surface residues (as well as the 
A

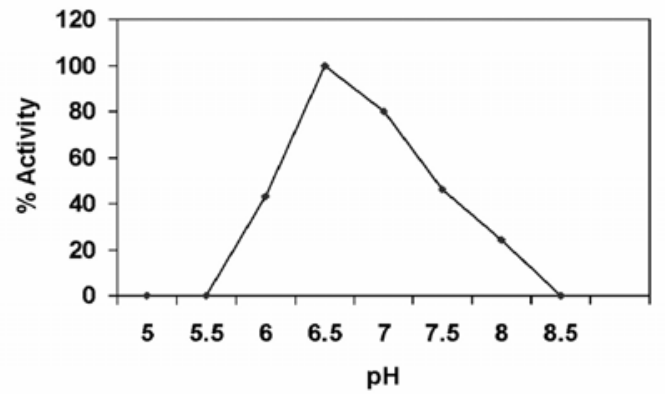

B

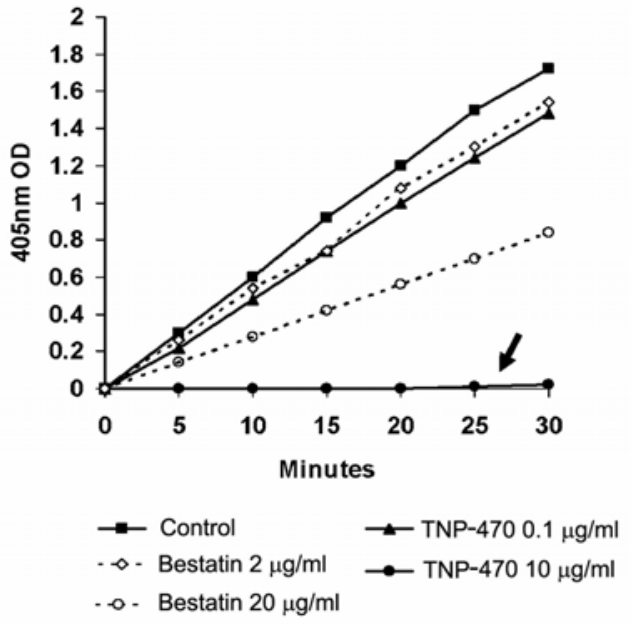

Fig. 6. In vitro activity of recombinant Encephalitozoon cuniculi methionine aminopeptidase type 2 (rEcMetAP2). A. The in vitro activity of $\mathrm{rEcMetAP} 2$ relative to $\mathrm{pH}$ of the assay buffer. B. rEcMetAP2 enzyme activity is inhibited by both TNP-470 and bestatin. The rEcMetAP2 activity present in 10 $\mu 1$ of eluate purified by FPLC using a MonoQ column was completely inhibited by $10 \mu \mathrm{g} / \mathrm{ml}$ of TNP-470 (arrow). (Fig. $6 \mathrm{~B}$ reprinted with permission from Weiss et al. 2003.)

absence of the $\mathrm{N}$-terminal poly-lysine region) that could be exploited in the design of more selective inhibitors of EcMetAP2. A detailed in silico model of EcMetAP2 using MODELLER has recently been published that confirms this analysis of EcMetAP2 (Bontems et al. 2003).

The FPLC fractions containing immunoreactive EcMetAP2 were assayed for enzyme activity using the method of Zhou (Zhou et al. 2000). EcMetAP2 was expressed in baculovirus as this system had been successfully utilized for the expression of enzymatically active HuMetAP2 that was subsequently used for crystallographic studies. Purified rEcMetAP2, expressed in baculovirus, had enzyme activity that could be inhibited by either TNP-470 or bestatin. TNP-470 is a specific inhibitor of MetAP2 related to fumagillin that binds covalently to His ${ }^{231}$. TNP-470 is known to inhibit microsporidia both in vitro and in vivo (Didier 1997, Coyle et al. 1998, Costa and Weiss 2000). Bestatin is a metalopeptidase inhibitor that inhibits microsporidia in vitro and would be expected to inhibit rEcMetAP2. This MetAP2 assay used $\mathrm{CoCl}_{2}$ as

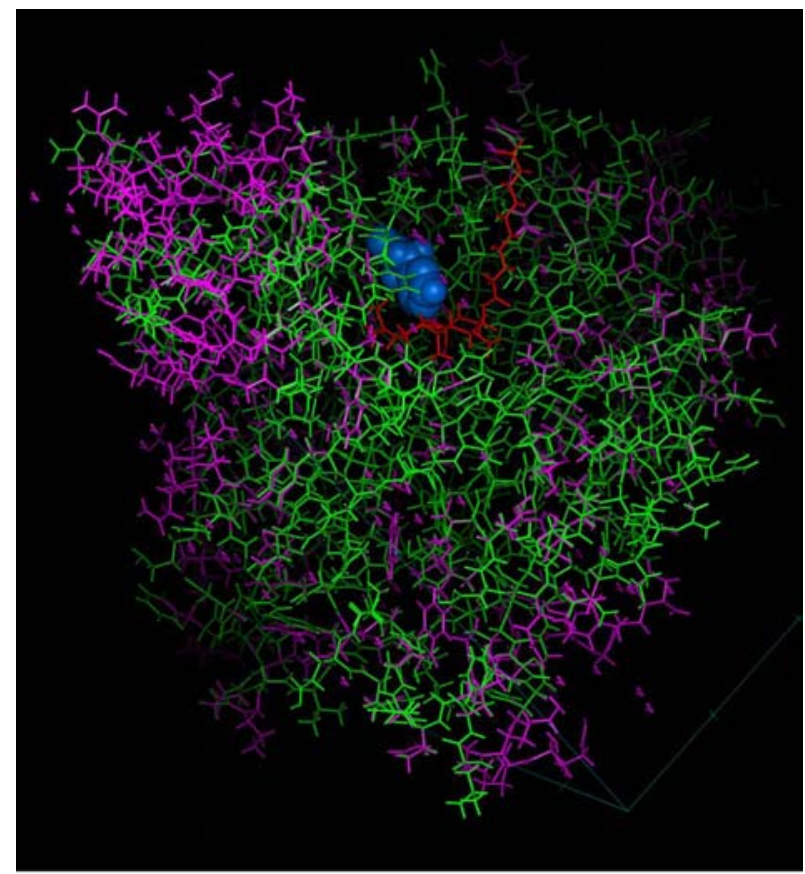

Fig. 7. In silico model of Encephalitozoon cuniculi methionine aminopeptidase type 2 . The published crystal structure of human MetAP2 (IBN5) and human MetAP2 complexed with fumagillin (IBOA) (Bontems et al. 2003), indicated in purple, was used to model the structure of EcMetAP2 (indicated in green) using MODELLER. Fumagillin in the active site is illustrated in red and the metal residues (cobalt) are illustrated in blue.

we had previously demonstrated that the addition of cobalt to the solution increased the measured enzyme activity (Weiss et al. 2001, 2003). While MetAP2 has been thought to have cobalt in its active site, recent data suggest that manganese may be the physiologically relevant metal for this class of enzymes (Wang et al. 2003). Studies have demonstrated that fumagillin derivatives display tissue- and species selectivity in their ability to inhibit MetAP2, suggesting that it may be possible to design selective MetAP2 inhibitors (Taylor 1993, Han et al. 2000). For example, pyridine-2-carboxylic acid derivatives have been demonstrated to be potent inhibitors of Saccharomyces cerevisiae MetAPs (Luo et al. 2003). Purified recombinant EcMetAP2 can now be used to screen other compounds in vitro for their ability to inhibit this microsporidian enzyme. Enterocytozoon bieneusi is non-cultivable and no small-animal models exist. Therefore, the identification and cloning of its MetAP2 gene would provide a tool for the development of an in vitro assay system to screen candidates as new therapeutic agents for the treatment of this organism.

In yeasts and higher eukaryotes, two isoforms (type 1 and type 2) of MetAP exist (Taylor 1993, Li and Chang 1995). Saccharomyces cerevisiae deficient in MetAP1 
(e.g. map1 that only have MetAP2) were killed by fumagillin or ovalicin, but yeast deficient in MetAP2 (e.g. map2 that contain only MetAP1) were not (Griffith et al. 1997, Sin et al. 1997). Deletion of both MetAP1 and MetAP2 is lethal to yeast. This data confirm that fumagillin selectively targets MetAP2 and not MetAP1. Data from the Encephalitozoon cuniculi genome project indicate that $E$. cuniculi does not have a methionine aminopeptidase type 1 gene (MetAP1) (Katinka et al. 2001). Microsporidia are, therefore, similar to mapl yeasts, which are killed by fumagillin. Since mammalian cells have both MetAP1 and MetAP2, it is likely that microsporidian MetAP2 would be an excellent therapeutic target for the development of selective drugs for the treatment of microsporidiosis.

Our laboratory group has successfully identified and characterized MetAP2 activity in several of the Microsporidia, demonstrated that MetAP2 inhibitors have activity in vitro and in small-animal models of microsporidiosis, cloned several microsporidian MetAP2 genes, performed phylogenetic studies on these MetAP2 genes, characterized microsporidian specific primers for
MetAP2 genes, done preliminary in silico analysis of EcMetAP2 and successfully purified and expressed enzymatically active rEcMetAP2. This information provides the groundwork for the development of new inhibitors of microsporidian MetAP2. The clinical limitations of fumagillin and its analogues relate to their ability to cause thrombocytopaenia and possible endothelial cell toxicity. Moreover, these compounds are noncompetitive inhibitors, i.e. they bind irreversibly to MetAP2, which may enhance toxicity when low-affinity binding occurs. Competitive inhibitors are preferred in drug design, since they are generally regarded as better able to exploit differences in binding efficiency between host and parasite enzymes, which usually results in less toxicity than that seen with non-competitive inhibitors. We believe that differences in the structure of this drug target between host and pathogen should permit the design of selective therapeutic agents with decreased host toxicity.

Acknowledgements. This work was supported by NIH grants AI31788 and AI52035.

\section{REFERENCES}

BONTEMS F., le FLOCH P., DUFFIEUX F., BIDERRE C., PEYRET P., LALLEMAND J.-Y. 2003: Homology modeling and calculation of the cobalt cluster charges of the Encephalitozoon cuniculi methionine aminopeptidase, a potential target for drug design. Biophys. Chem. 105: 2943.

CALI A., KOTLER D.P., ORENSTEIN J.M. 1993: Septata intestinalis n. g., n. sp., an intestinal microsporidian associated with chronic diarrhea and dissemination in AIDS patients. J. Eukaryot. Microbiol. 40: 101-112.

CALI A., TAKVORIAN P.M. 2003: Ultrastructure and development of Pleistophora ronneafiei n. sp., a microsporidium (Protista) in the skeletal muscle of an immunocompromised individual. J. Eukaryot. Microbiol. 50: 7785.

CALI A., TAKVORIAN P.M., LEWIN S., RENDEL M., SIAN C.S., WITTNER M., TANOWITZ H.B., KEOHANE E., WEISS L.M. 1998: Brachiola vesicularum, $\mathrm{n}$. g., n. sp., a new microsporidium associated with AIDS and myositis. J. Eukaryot. Microbiol. 45: 240-251.

CHANG Y.H., TEICHERT U., SMITH J.A. 1990: Purification and characterization of a methionine aminopeptidase from Saccharomyces cerevisiae. J. Biol. Chem. 265: 19892-19897.

COSTA S.F., WEISS L.M. 2000: Drug treatment of microsporidiosis. Drug. Resist. Updat. 3: 384-399.

COYLE C., KENT M., TANOWITZ H.B., WITTNER M., WEISS L.M. 1998: TNP-470 is an effective antimicrosporidial agent. J. Infect. Dis. 177: 515-518.

COYLE C.M., WEISS L.M., RHODES L.V. 3rd, CALI A., TAKVORIAN P.M., BROWN D.F., VISVESVARA G.S., XIAO L., NAKTIN J., YOUNG E., GARECA M., COLASANTE G., WITTNER M. 2004: Fatal myositis due to the microsporidian Brachiola algerae, a mosquito pathogen. N. Engl. J. Med. 351: 42-47.

DENGJEL B., ZAHLER M., HERMANNS W., HEINRITZI K., SPILLMANN T., THOMSCHKE A., LOSCHER T., GOTHE R., RINDER H. 2001: Zoonotic potential of Enterocytozoon bieneusi. J. Clin. Microbiol. 39: 4495-4499.

DEPLAZES P., MATHIS A., WEBER R. 2000: Epidemiology and zoonotic aspects of microsporidia of mammals and birds. Contrib. Microbiol. 6: 236-260.

DESPORTES I., LE CHARPENTIER Y., GALIAN A., BERNARD F.B., COCHAND-PRIOLLET B., LAVERGNE A., RAVISSE P., MODIGLIANI R. 1985: Occurrence of a new microsporidian: Enterocytozoon bieneusi $\mathrm{n}$. g., n. sp., in the enterocytes of a human patient with AIDS. J. Protozool. 32: 250-254.

DIDIER E.S. 1997: Effects of albendazole, fumagillin, and TNP-470 on microsporidial replication in vitro. Antimicrob. Agents Chemother. 41:1541-1546.

DIDIER E.S., DIDIER P.J., FRIEDBERG D.N., STENSON S.M., ORENSTEIN J.M., YEE R.W., TIO F.O., DAVIS R.M., VOSSBRINCK C., MILLICHAMP N., SHADDUCK J.A. 1991: Isolation and characterization of a new human microsporidian, Encephalitozoon hellem (n. sp.) from three AIDS patients with keratoconjunctivitis. J. Infect. Dis. 163: 617-621.

DIDIER E.S., MADDRY J.A., KWONG C.D., GREEN L.C., SNOWDEN K.F., SHADDUCK J.A. 1998: Screening of compounds for antimicrosporidial activity in vitro. Folia Parasitol. 45: 129-139.

DIDIER E.S., MARTIN A.D., STOVALL M.E., ALVAREZ X., MITTLEIDER D., GREEN L.C., BOWERS L.C., PLAUCHE A.K., DIDIER P.J., BRINDLEY P.J. 2003:. Methionine aminopeptidase 2 expression in microsporidia. J. Eukaryot. Microbiol. 50: 569-571. 
DIDIER E.S., ROGERS L.B., ORENSTEIN J.M., BAKER M.D., VOSSBRINCK C.R., VAN GOOL T., HARTSKEERL R., SOAVE R., BEAUDET L.M. 1996: Characterization of Encephalitozoon (Septata) intestinalis isolates cultured from nasal mucosa and bronchoalveolar lavage fluids of two AIDS patients. J. Eukaryot. Microbiol. 43: 34-43.

DIETERICH D.T., LEW E.A., KOTLER D.P., POLES M.A., ORENSTEIN J.M. 1994: Treatment with albendazole for intestinal disease due to Enterocytozoon bieneusi in patients with AIDS. J. Infect. Dis. 169: 178-183.

DOWD S.E., GERBA C.P., PEPPER I.L. 1998: Confirmation of the human-pathogenic microsporidia Enterocytozoon bieneusi, Encephalitozoon intestinalis, and Vittaforma corneae in water. Appl. Environ. Microbiol. 64: 33323335.

FIELD A.S., MARRIOTT D.J., MILLIKEN S.T., BREW B.J., CANNING E.U., KENCH J.G., DARVENIZA P., HARKNESS J.L. 1996: Myositis associated with a newly described microsporidian, Trachipleistophora hominis, in a patient with AIDS. J. Clin. Microbiol. 34: 2803-2811.

FRANSSEN F.F.J., LUMEIJ J.T., VANKNAPEN F. 1995: Susceptibility of Encephalitozoon cuniculi to several drugs in vitro. Antimicrob. Agents Chemother. 39: 1265-1268.

FREEMAN M., YOKOYAMA H., OGAWA K. 2004: A microsporidian parasite of the genus Spraguea in the nervous tissues of the Japanese anglerfish Lophius litulon. Folia Parasitol. 51: 167-176.

GRIFFITH E.C., SU Z., TURK B.E., CHEN S., CHANG Y.H., WU Z., BIEMANN K., LIU J.O. 1997: Methionine aminopeptidase (type 2) is the common target for angiogenesis inhibitors AGM-1470 and ovalicin. Chem. Biol. 4: 461-471.

HAN C.K., AHN S.K., CHOI N.S., HONG R.K., MOON S.K., CHUN H.S., LEE S.J., KIM J.W., HONG C.I., KIM D., YOON J.H., NO K.T. 2000: Design and synthesis of highly potent fumagillin analogues from homology modeling for a human MetAP-2. Bioorg. Med. Chem. Lett. 10: 39-43.

HIGGINS M.J., KENT M.L., MORAN J.D., WEISS L.M., DAWE S.C. 1998: Efficacy of the fumagillin analog TNP470 for Nucleospora salmonis and Loma salmonae infections in chinook salmon Oncorhynchus tshawytscha. Dis. Aquat. Org. 34: 45-49.

HOLLISTER W.S., CANNING E.U., WILLCOX A. 1991: Evidence for widespread occurrence of antibodies to Encephalitozoon cuniculi (Microspora) in man provided by ELISA and other serological tests. Parasitology 102: 3343.

KATINKA M.D., DUPRAT S., CORNILLOT E., MÉTÉNIER G., THOMARAT F., PRENSIER G., BARBE V., PEYRETAILLADE E., BROTTIER P., WINCKER P., DELBAC F., El ALAOUI H., PEYRET P., SAURIN W., GOUY M., WEISSENBACH J., VIVARÈS C.P. 2001: Genome sequence and gene compaction of the eukaryote parasite Encephalitozoon cuniculi. Nature 414: 450-453.

KATIYAR S.K., GORDON V.R., MCLAUGHLIN G.L., EDLIND T.D. 1994: Antiprotozoal activities of benzimidazoles and correlations with beta-tubulin sequence. Antimicrob. Agents Chemother. 38: 2086-2090.
KATSNELSON H., JAMIESON C.A. 1952: Control of Nosema disease of honeybees with fumagillin. Science 115: 70-72.

KEELING P.J. 2003: Congruent evidence from alpha-tubulin and beta-tubulin gene phylogenies for a zygomycete origin of microsporidia. Fungal Genet. Biol. 38: 298-309.

KEELING P.J., DOOLITTLE W.F. 1996: Methionine aminopeptidase-1: the MAP of the mitochondrion? Trends Biochem. Sci. 21: 285-286.

KEOHANE E.M., ORR G.A., TAKVORIAN P.M., CALI A., TANOWITZ H.B., WITTNER M., WEISS L.M. 1996: Purification and characterization of a microsporidian polar tube protein. Mol. Biochem. Parasitol. 79: 255-259.

KEOHANE, E.M., ORR, G.A., ZHANG, H.S., TAKVORIAN, P.M., CALI, A., TANOWITZ, H.B., WITTNER M., WEISS L.M. 1998: The molecular characterization of the major polar tube protein gene from $E n$ cephalitozoon hellem, a microsporidian parasite of humans. Mol. Biochem. Parasitol. 94: 227-236.

LI X., CHANG Y.H. 1995: Amino-terminal protein processing in Saccharomyces cerevisiae is an essential function that requires two distinct methionine aminopeptidases. Proc. Natl. Acad. Sci. USA 92: 12357-12361.

LI X., CHANG Y.H. 1996: Evidence that the human homologue of a rat initiation factor-2 associated protein (p67) is a methionine aminopeptidase. Biochem. Biophys. Res. Commun. 227: 152-159.

LIU S., WIDOM J., KEMP C.W., CREWS C.M., CLARDY J. 1998: Structure of human methionine aminopeptidase-2 complexed with fumagillin. Science 282: 1324-1327.

LORES B., LOPEZ-MIRAGAYA I., ARIAS C., FENOY S., TORRES J., del AGUILA C. 2002: Intestinal microsporidiosis due to Enterocytozoon bieneusi in elderly human immunodeficiency virus-negative patients from Vigo, Spain. Clin. Infect. Dis. 34: 918-921.

LOWTHER W.T., MATTHEWS B.W. 2000: Structure and function of the methionine aminopeptidases. Biochim. Biophys. Acta 1477: 157-167.

LUO Q.L., LI J.Y., LIU Z.Y., CHEN L.L., LI J., QIAN Z., SHEN Q., LI Y., LUSHINGTON G.H., YE Q.Z., NAN F.J. 2003: Discovery and structural modification of inhibitors of methionine aminopeptidases from Escherichia coli and Saccharomyces cerevisiae. J. Med. Chem. 46: 2631-2640.

MILLERSHIP J.J., CHAPPELL C., OKHUYSEN P.C., SNOWDEN K.F. 2002: Characterization of aminopeptidase activity from three species of microsporidia: Encephalitozoon cuniculi, Encephalitozoon hellem, and Vittaforma corneae. J. Parasitol. 88: 843-848.

MOLINA J.M., TOURNEUR M., SARFATI C., CHEVRET S., DE GOUVELLO A., GOBERT J.G., BALKAN S., DEROUIN F., Agence Nationale de Recherches sur le SIDA 090 Study Group 2002: Fumagillin treatment of intestinal microsporidiosis. N. Engl. J. Med. 346: 19631969.

RABODONIRINA M., COTTE L., RADENNE S., BESADA E., TREPO C. 2003: Microsporidiosis and transplantation: a retrospective study of 23 cases. J. Eukaryot. Microbiol. 50: 583 . 
ROSBERGER D.F., SERDAREVIC O.N., ERLANDSON R.A., BRYAN R.T., SCHWARTZ D.A., VISVESVARA G.S., KEENAN P.C. 1993: Successful treatment of microsporidial keratoconjunctivitis with topical fumagillin in a patient with AIDS. Cornea 12: 261-265.

SALI A., OVERINGTON J.P. 1994: Derivation of rules for comparative protein modeling from a database of protein structure alignments. Protein Sci. 3: 1582-1596.

SHADDUCK J.A. 1980: Effect of fumagillin on in vitro multiplication of Encephalitozoon cuniculi. J. Protozool. 27: 202-208.

SHEORAN A.S., FENG X., KITAKA S., GREEN L., PEARSON C., DIDIER E.S., CHAPMAN S., TUMWINE J.K., TZIPORI S. 2005: Purification of Enterocytozoon bieneusi from stool and production of specific antibodies. J. Clin. Microbiol. 43: 387-392.

SILVEIRA H., CANNING E.U. 1995: Vittaforma corneae n. comb. for the human microsporidium Nosema corneum Shadduck, Meccoli, Davis and Font, 1990, based on its ultrastructure in the liver of experimentally infected athymic mice. J. Eukaryot. Microbiol. 42: 158-165.

SIN N., MENG L., WANG M.Q., WEN J.J., BORNMANN W.G., CREWS C.M. 1997: The anti-angiogenic agent fumagillin covalently binds and inhibits the methionine aminopeptidase, MetAP-2. Proc. Natl. Acad. Sci. USA 94: 6099-6103.

SLAMOVITS C.H., FAST N.M., LAW J.S., KEELING P.J. 2004: Genome compaction and stability in microsporidian intracellular parasites. Curr. Biol. 14: 891-896.

SPRAGUE V., BECNEL J.J., HAZARD E.I. 1992: Taxonomy of phylum Microspora. Crit. Rev. Microbiol. 18: 285-395.

TAKVORIAN P.M., CALI A. 1986: The ultrastructure of spores (Protozoa: Microsporida) from Lophius americanus, the angler fish. J. Protozool. 33: 570-575.

TAKVORIAN P.M., CALI A. 1994: Enzyme histochemical identification of the Golgi apparatus in the microsporidian, Glugea stephani. J. Eukaryot. Microbiol. 41: 63S-64S.

TAYLOR A. 1993: Aminopeptidases: structure and function. FASEB J. 7: 290-298.

TUMWINE J.K., KEKITIINWA A., NABUKEERA N., AKIYOSHI D.E., BUCKHOLT M.A., TZIPORI S. 2002: Enterocytozoon bieneusi among children with diarrhea at-

Received 13 October 2004 tending Mulago Hospital in Uganda. Am. J. Trop. Med. Hyg. 67: 299-303.

TURK B.E., SU Z., LIU J.O. 1998: Synthetic analogues of TNP-470 and ovalicin reveal a common molecular basis for inhibition of angiogenesis and immunosuppression. Bioorg. Med. Chem. 6: 1163-1169.

WANG J., SHEPPARD G.S., LOU P., KAWAI M., PARK C., EGAN D.A., SCHNEIDER A., BOUSKA J., LESNIEWSKI R., HENKIN J. 2003: Physiologically relevant metal cofactor for methionine aminopeptidase-2 is manganese. Biochemistry 42: 5035-5042.

WEBER R., BRYAN R.T. 1994: Microsporidial infections in immunodeficient and immunocompetent patients. Clin. Infect. Dis. 19: 517-521.

WEBER R., DEPLAZES P., FLEPP M., MATHIS A., BAUMANN R., SAUER B., SCHNEIDER A., BOUSKA J., LESNIEWSKI R., HENKIN J. 1997: Cerebral microsporidiosis due to Encephalitozoon cuniculi in a patient with human immunodeficiency virus infection. N. Engl. J. Med. 336: 474-478.

WEBER R., DEPLAZES P., SCHWARTZ D. 2000: Diagnosis and clinical aspects of human microsporidiosis. Contrib. Microbiol. 6: 166-192.

WEISS L.M. 2000: Molecular phylogeny and diagnostic approaches to microsporidia. Contrib. Microbiol. 6: 209235.

WEISS L.M., COSTA S.F., ZHANG H. 2001: Microsporidian methionine aminopeptidase type 2. J. Eukaryot. Microbiol. 48 (Suppl.): 88S-90S.

WEISS L.M., EDLIND T.D., VOSSBRINCK C.R., HASHIMOTO T. 1999: Microsporidian molecular phylogeny: the fungal connection. J. Eukaryot. Microbiol. 46: 17S-18S.

WEISS L.M., ZHOU G.C., ZHANG H. 2003: Characterization of recombinant microsporidian methionine aminopeptidase type 2. J. Eukaryot. Microbiol. 50: 597-599.

WILLIAMS B.A., HIRT R.P., LUCOCQ J.M., EMBLEY T.M. 2002: A mitochondrial remnant in the microsporidian Trachipleistophora hominis. Nature 418: 865-869.

WITTNER M., WEISS L.M. 1999: The Microsporidia and Microsporidiosis. ASM Press, Washington, D.C., 577 pp.

ZHOU Y., GUO X.C., YI T., YOSHIMOTO T., PEI D. 2000: Two continuous spectrophotometric assays for methionine aminopeptidase. Anal. Biochem. 280: 159-165.

Accepted 25 January 2005 